\title{
Exploring Support Strategies for High School Mathematics Teachers from Underachieving Schools
}

\author{
D. Brijlall ${ }^{1}$ and A. Maharaj ${ }^{2}$ \\ ${ }^{1}$ Department of Mathematics, Statistics and Physics, Durban, University of Technology, \\ 37 Halpin Avenue, Reservoir Hills, 4091 South Africa \\ ${ }^{2}$ School of Mathematics, Physics and Computer Science, University of KwaZulu-Natal, \\ 27 Bhoola Road Effingham, Durban 4000 South Africa \\ Telephone: ${ }^{1<+27313732126>,{ }^{2}<+27312601021>}$

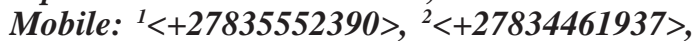 \\ E-mail: ${ }^{1<\text { deonarainb@dut.ac.za }>,{ }^{2}<\text { maharaja32@ukzn.ac.za }>}$
}

KEYWORDS Pedagogical Content Knowledge. Practicing Teachers. Underachieving Schools

\begin{abstract}
Algebra, trigonometry and calculus concepts are dealt with in grades 10 to 12 of South African high school topics, as prescribed by the Curriculum and Assessment Policy Statement. This paper reports on a study exploring practicing teachers' subject matter knowledge of certain topics they were expected to teach. The theoretical perspectives for the design and analysis of this study were based on Shulman's conceptual framework. This study was a qualitative case study $(\mathrm{n}=28)$. Practising teachers from the Pinetown district in KwaZulu-Natal participated in this mathematics' teacher intervention. Focused tasks on algebra, trigonometry and calculus were designed and administered to those teachers. The researchers analysed the data from those tests and found that certain areas of their pedagogical content knowledge required attention.
\end{abstract}

\section{INTRODUCTION}

According to Long (2003: 194), "the emphasis on improving teachers' subject knowledge is tied to the belief that this will improve mathematics achievement" of learners they teach. Even (1990) also focused on this aspect and referred to reforms in education in the United Kingdom; for example, the Carnegie Task Force and Holmes Group in 1986, that were designed to improve the content and professional knowledge of teachers. Kilpatrick et al. (2001: 372) also affirmed this idea in the sense that they believed "knowledge of content to be taught is the cornerstone of teaching for proficiency." They believed that improving teachers' knowledge is vital in developing students' mathematical ability and proficiency. Pedagogical content knowledge (PCK) and content knowledge (CK) are crucial facets of teacher competence. Kleickmann et al. (2013) constructed tests to access mathematics teachers' CK and PCK. Those tests were constructed to investigate how teacher education

Address for correspondence:

Prof. Deonarain Brijlall

Department of Mathematics,

Durban University of Technology, 37 Halpin Avenue,

Reservoir Hills, 4091 South Africa

E-mail: deonarainb@dut.ac.za affects the development of CK and PCK among mathematics' teachers in Germany. They found large differences in CK and PCK between the beginning and end of participants' initial teacher education. McNeill and Knight (2013) examined how three professional development workshop series, in the context of scientific argumentation, impacted on 70 teachers' PCK. Their findings suggest that the workshops were successful in those teachers' development of PCK for scientific argumentation in relation to the structural components of students' science writing. The authors of this paper observed that current reforms in South Africa (for example at the University of KwaZulu-Natal, University of the Witwatersrand, Nelson Mandela Metropolitan University) were also concentrating efforts on strengthening the pedagogical content knowledge of teachers. This study therefore focused on exploring ways in addressing the pedagogical content knowledge of teachers, especially those teaching at schools which were classified as underachieving. This classification was done by the provincial department of education based on those schools' senior certificate examination performances. If the overall matric pass rate was below sixty percent then the schools were placed in this category. For their project the researchers decided on designing a suitable support programme to attempt an improvement 
on the subject matter knowledge of those selected teachers' needs. The research question for this study was: What do support strategies reveal about the pedagogical content knowledge of practising teachers from underachieving schools? This study was funded by the UKZN-ESKOM Mathematics Project. Another paper by Maharaj (2013) reports on data from the pre-test and uses APOS as a theoretical framework. The study reported in this paper utilised that data and makes a contribution to the theory of mathematical fluency.

\section{Background to UKZN-ESKOM Mathematics Project}

In 2010 a meeting was arranged between interested representatives from the Electricity Supply Commission (ESKOM) in South Africa and some academics from the School of Mathematical Sciences at the University of KwaZulu-Natal (UKZN). At that meeting it became apparent that the relevant role-players from ESKOM were concerned about the quality of graduates they were working with, and they felt a need to engage with interested role-players in mathematics at university level. The meeting was attended by a mathematics representative from the Department of Education's (DoE's) local district, members of the School of Mathematical Sciences and School of Education of UKZN, a member of an NGO (Non-Government Organisation) who actively promotes the teaching and learning of mathematics at secondary school level, and relevant stakeholders from ESKOM.

At the meeting it was suggested that if things are put right in the teaching and learning of mathematics then other aspects that they considered to be important will fall into place. One aspect was to devise support programmes for grade 11 and 12 mathematics teachers and learners. This includes upgrading of teacher qualifications and abilities, and the provision of quality support material for both teachers and pupils. The aspect on the support for teachers and pupils was one of the focus areas of the UKZN-ESKOM Mathematics Project, which was setup in 2011.

\section{Conceptual Framework}

The conceptions of what constitutes teachers' subject matter knowledge or content knowledge has changed from the beginning of the twentieth century. At the beginning of the century it was described in qualitative terms which made it very difficult to measure or evaluate the content knowledge of teachers. Prior to this, towards the end of the nineteenth century this perception shifted with the emphasis being placed on the number of courses taken by teachers and also their performance in standardised tests. Shulman's Presidential Address in 1986 (as cited in Even 1990: 322) saw a return to assessing teachers' subject matter knowledge in quantitative terms. According to Even (1990: 322),

"analysing what it means to know mathematics, has some promise to contribute to the improvement of the quality of subject matter preparation of teachers and therefore the quality of teaching and learning."

Shulman's main area of concern was: How could a student teacher transform his/her expertise of subject matter into a form that could be presented to school pupils? He argued that with content expertise the teacher could correct flaws in textbooks and also offer explanations to pupils. Shulman believed that both pedagogical expertise and content knowledge are vitally important for effective teaching.

"Mere content knowledge is likely to be as useless pedagogically as content-free skill. But to blend properly the two aspects of a teacher's capacities requires that we pay as much attention to the content aspects of teaching as we have recently devoted to the elements of the teaching process" (Shulman 1986: 8).

Shulman began to probe teacher understanding and the transmission of content knowledge from the teacher to the pupil. In his research several questions came to the fore which he tried to find answers to and one of the important domains that Shulman focused on was content knowledge.

Shulman distinguished among three categories of content knowledge, namely:

o Subject Matter Content Knowledge: This refers to the knowledge that the teacher possesses about his/her subject. This goes beyond the knowledge of facts and concepts pertaining to a particular subject, and encompasses knowledge about why concepts and topics are important to a subject, which topics are central and which are peripheral.

o Pedagogical Content Knowledge (PCK): This goes beyond the knowledge of a par- 
ticular subject and incorporates knowledge on how to teach the particular subject. This includes knowledge of topics most often taught in a particular subject (for this study tasks in algebra, trigonometry and calculus), the most important and appropriate examples that are used, and the most meaningful forms of representations used. All these come from experience and practice. Pedagogical content knowledge also includes knowledge about what makes a particular topic easy or difficult for pupils to understand, the common misconceptions that pupils may have on a particular topic and the strategies on how to deal with these issues.

o Curricular Knowledge. This refers to the teacher's knowledge firstly about his own subject matter, knowledge about the content taught in preceding years and the content to be taught in years that follow. In this way the teacher can adequately teach pupils present content as he is aware of what they already know and he is also aware of how the current topic will be extended in future years. Curricular knowledge also refers to knowledge about other subjects and how this links to knowledge in the teacher's particular subject and field. In this way the teacher can relate what the pupil is learning in one subject to what is being taught in another subject and this makes learning more meaningful and relevant.

Shulman's ideas on content knowledge were contrary to the thinking of the 1980's. He went against the reforms of the time where the focus was on "how to improve teaching as both an activity and a profession” (Shulman 1987: 3). Shulman's work resulted in PCK being a focus of mathematics education research in South Africa. For example, one of the authors has explored links between PCK and classroom practice in a calculus class at a South African university (Brijlall and Isaac 2011). That study was contextualized at a higher education institution in South Africa where two university lecturers were lecturing to a second year undergraduate teacher trainee class $(\mathrm{n}=78)$. The research was conceptualised in terms of Vygotsky's educational theory and the process of scaffolding. The study revealed that those two university lecturers portrayed a strong link between PCK and classroom practice.
Built on Shulman's notion of PCK, Ball et al. (2008) developed a practice-based theory of content knowledge for mathematics teaching in the United States of America. Arising from the study by Ball et al. (2008), Beswick et al. (2012) designed research instruments to assess aspects of teachers' knowledge in an Australian context. Research in teacher knowledge in mathematics teaching is gaining momentum internationally.

\section{METHODOLOGY}

"Methodology refers to the coherent group of methods that complement one another and that have the 'goodness of fit' to deliver data and findings that will reflect the research question and suit the research purpose" (Henning 2004: 36). According to Cohen et al. (2007: 47), research methods are a "range of approaches used in educational research to gather data which are to be used as a basis for inference and interpretation, for explanation and prediction." With these definitions in mind the approach that the researchers used for their research was a mixed-mode case study as they felt that this approach would best deliver their data, suit their research purpose and assist reflection on their research question.

\section{The Case Study}

In any type of dialogue it is effective when one uses a particular instance to illustrate something that is more general. It is easier to engage with your audience when you talk about real people and events instead of discussing theories and ideas that are abstract (Maree and Pieterson 2007). People generally understand an idea better if an example is used to illustrate the idea. We are all familiar with specific details and that a single instance assists us to see how the abstract principles fit together (Maree and Pieterson 2007). “A case study is a specific instance that is frequently designed to illustrate a more general principle” (Nisbet and Watt as cited in Cohen et al. 2007: 253). This research was specific in that the researchers invited twenty eight teachers from underachieving schools, which offered mathematics at the senior certificate level.

\section{Participants}

The participants in our research were 28 inservice teachers. The teachers were chosen for two reasons: firstly the teachers were involved 
in the UKZN-ESKOM Mathematics Project and were therefore convenient and accessible, and secondly they were chosen purposively. Access is a key issue in research and it is a factor that must be considered early in the research procedure (Cohen et al. 2007: 109). The selection of the participants was done by the chief subject advisor for the Pinetown District, who was of the opinion that the teachers would benefit from the programme. The schools those teachers worked in were classified as underachieving.

\section{Ethical Issues}

"A major ethical dilemma is that which requires researchers to strike a balance between the demands placed on them as professional scientists in pursuit of truth, and their subjects' rights and values potentially threatened by the research" (Cohen et al. 2007: 51). In terms of ethical considerations the researchers followed the procedures as stipulated by the university research office. Participation by those teachers was totally voluntary and their confidentiality, privacy and anonymity were assured. The consent letters included details of the study and data collection procedures. The participants were also assured that if they chose to be part of the study they could withdraw at any time without being prejudiced in any way.

\section{Validity and Reliability}

In qualitative research "validity might be addressed through the honesty, depth, richness and scope of the data achieved, the participants, the extent of the triangulation and the disinterestedness or objectivity of the researcher" (Winter as cited in Cohen et al. 2007: 133). Validity can be improved through careful sampling, using the appropriate instruments and data analysis techniques. Validity is not something that can be achieved absolutely but it can be maximized. According to Cohen et al. (2007: 149), reliability can be seen as the correlation between the researcher's recorded data and what actually happens in the natural setting of the research. This the researchers achieved by triangulating the data.

\section{Data Generating Instruments}

Primary data was generated from the written responses of those teachers, to designed tasks.
Siedel's model consists of three essential categories namely: noticing, collecting and reflecting (Siedel et al. 2004). These categories are interlinked and necessary in the qualitative data analysis process. Sometimes while you are analysing and reflecting on the data that you have collected, you notice gaps in the data. You have to therefore go back to collect additional data in order to fill in the gaps.

The researchers noticed that quality of the students they were getting at the university to study mathematics was not of the expected standard. To try to address this they embarked on a support programme for teachers. The intention was to improve the PCK of the participants. Suitable tasks in algebra, trigonometry and calculus were designed to collect data to gauge the PCK of those teachers (for the respective sections). The written responses to those tasks were statistically analysed. Thereafter sample written responses were analysed to consolidate implications of the statistical analysis. This was the procedure adopted (based on Fig. 1) to make relevant findings, which are presented in the next section.

\section{RESULTS AND DISCUSSION}

These are presented under the following sub-sections: Algebra, Trigonometry, and Calculus. Note that not all 28 participants attempted the different tasks, since on the different days some of them were absent and others chose not to respond.

\section{Algebra}

The algebra tasks, statistical analysis and discussion of data are now presented.

Box 1: Algebra tasks on factors, equations and inequations

1. Write the following number as a product of its factors: $42=$

2. In each of the following identify as fully as possible the type of the equation. In each case give an explanation of how you arrived at your conclusion regarding the type of equation.

$2.1 \quad \chi(\chi-4)=-3$

$2.2 \quad 49-4(-4-\chi)=0$

$2.3 \chi+\frac{8}{\chi}=6$

$2.4 \quad \chi^{2}(\mathrm{x}+2)=5 \chi+6$

$2.55^{x+1}+5^{1-x}=26$

3. Solve for $\mathrm{x}$ in the inequality: $\chi(\chi+4) \geq 5$ 


\section{Box 2: Algebra tasks on functions}

4. For each of 4.1 to 4.2 the following is required Next to the function identify the type as linear, quadratic, logarithmic, exponential, hyperbolic or cubic. In each case, on the right hand side indicate (a) the domain and (b) the range.

$4.1 f(\chi)=-2 \chi^{2}+4$
Type

$4.2 g(x)=\frac{3}{\chi+1}$

Type

$4.3 h(\chi)=2^{x}$ (a) Domain:

(b) Range:

(a) Domain:

(b) Range:

(b) Range: (a) Domain:

Table 1 and Figure 1 give the statistical analysis for participant performance for the algebra tasks. Note that the lower quartile indicates that one-fourth of the marks were below 18.5 (out of a total of 30). This implies that about $25 \%$ of those teachers had an unsatisfactory PCK for algebra content, since their achievement was

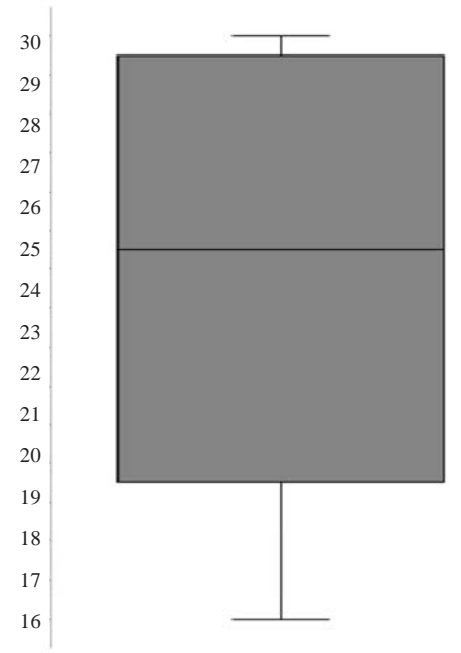

Fig. 1. Box and whisker plot illustrating performance in algebra
$60 \%$ and below. It was encouraging that the median mark was above $80 \%$ (see Table 1 ). This implies that about $50 \%$ of those teachers had a fairly good PCK for algebra. The implication here is that the support provided, prior to the teachers taking those tasks, was of help to them. This was a possibility since the tasks for algebra were given on the first day, after a three hour session on school algebra was facilitated.

The sections in which the teachers had a fairly good level of PCK were: prime factorization, linear equations, quadratic equations, cubic equations, exponential equations (see Box 1 for the tasks on the preceding sections), and identification of functions (see Box 2). Sections in which those teachers displayed unsatisfactory PCK were: inequalities (see Box1, number 3) and domain and range (see Box 2). Furthermore with regards to inequalities there was a lack of understanding in many cases as to how to go about obtaining the solution. For example, the correct techniques of finding the critical values and then investigating the signs in the different regions when using the number-line technique for solving inequalities. Looking at domain and range there were difficulties with: (1) use of correct notation, and (2) little if any understanding of these concepts. For example, for number 4.1 in Box 2, for the range one of the responses was: $y \varepsilon R>4$. The implication here is that when developing the PCK of mathematics teachers, the correct use of notation and these concepts need to be strengthened.

By analyzing the spread of the data from the box and whisker plot we notice that the data is "skewed to the left" which means that the frequency of high marks is greater. Each quartile marks $25 \%$ of the data, which means that $50 \%$ of the teachers scored marks 24.5 and higher, and only $25 \%$ of teachers scored less than 18.5 (see Fig. 2).

Standard deviation (see Table 1) refers to how much the data differs from the mean on average, meaning most of the data is within the range [18.65, 29.25]. The general conclusion is that the algebra section was answered fairly well, with a few sections that need to be addressed.

Table 1: Statistical analysis for performance in algebra

\begin{tabular}{lllccccc}
\hline $\begin{array}{l}\text { Number } \\
\text { wrote }\end{array}$ & $\begin{array}{l}\text { Minimum } \\
\text { mark }\end{array}$ & $\begin{array}{l}\text { Lower } \\
\text { quartile }\end{array}$ & Median & $\begin{array}{c}\text { Upper } \\
\text { quartile }\end{array}$ & $\begin{array}{c}\text { Maximum } \\
\text { mark }\end{array}$ & $\begin{array}{c}\text { Mean } \\
\text { deviationdard }\end{array}$ \\
\hline 20 & 15 & 18.5 & 24.5 & 29.5 & 30 & 23.95 & 5.3 \\
\hline
\end{tabular}




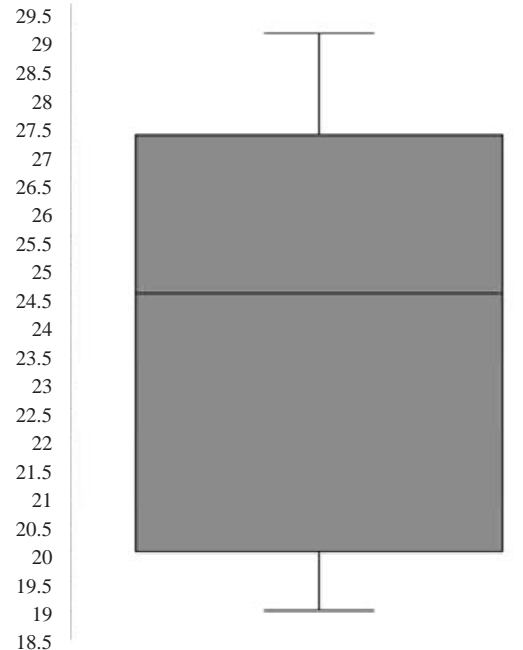

Fig. 2. Box and whisker illustrating performance in calculus

\section{Trigonometry}

The trigonometry tasks, followed by the statistical analysis and discussion of data are now presented.

\section{Box 3: Trigonometry tasks}

1. If $3 \sin \theta=1$, where $\theta$ is an acute angle, determine $\tan \theta$.

2. Draw rough sketches of the following $2.1 \mathrm{y}=\sin \theta$, for $0^{\prime \prime} \leq \theta 360^{\prime \prime}$

$2.2 \mathrm{y}=\cos \theta$, for $0 " \leq \theta \leq 360 "$

3. What is the range of the function defined by $y=$ $\sin \theta$ ?

3.1 What can be concluded from this about the range of the function defined by $y=\sin ^{2} \theta$ ?

4. Solve for $\theta$ in the equation $2 \cos ^{2} \theta-3 \cos \theta=$

2, for $0 " \leq \theta \leq 360$ "
5. For which value(s) of $\theta$ is the expression $\frac{\tan \theta}{\sqrt{1+2 \cos \theta}}$
undefined?

The following tasks (see Box 3) were answered well and contributed to the median of 24.5 (see Table 2): (a) solve for theta, trigonometry ratios, (b) sketching graphs of trigonometric functions, (c) range of trigonometry functions
(Box 3, number 3), and (d) disguised quadratic trigonometric equation (Box 3, number 4).

Looking at the box and whisker plot (see Fig. 3) one can see that the data is fairly symmetric which indicates that the marks are fairly evenly distributed. This is also reflected in the fact that the mean and the median (see Table 2) are very close in value, that is, for symmetric data the mean is almost equal to the median. We would expect the responses of those teachers to be more concentrated towards a good PCK for the tasks indicated in the previous paragraph. This was confirmed from an observation of their written responses.

The researchers note from the box and whisker plot (see Fig. 2) that the lower quartile for trigonometry was 20 , out of a total of 30 . This implies that $25 \%$ of those teachers had a PCK for trigonometry content of less than $70 \%$. The tasks that led to this were: (a) undefined expressions (Box 3, number 5), and (b) range of trigonometry functions (Box 3, number 3.1). Note that the latter task required deductive reasoning. The implication here is that the development of PCK for mathematics teachers should encompass deductive reasoning.

With respect to the undefined expressions most of those teachers knew that they had to equate the denominator to zero. However they were unable to solve the resulting equation and many of them did not consider the case where $\tan \theta$ is undefined. With regard to the range of trigonometry function $y=\sin ^{2} \theta$ (see Box 3, numbers 3 and 3.1), this dealt with squaring the sine function and then interpreting what would happen to the range. This was answered poorly, they didn't realise that the range would simply change from $[-1,1]$ to $[0,1]$, based on the principle that squaring any number would result in a zero or positive values.

In conclusion, since the lower quartile is below $70 \%$ the implication is that the PCK of teachers need to be developed for trigonometry, especially for undefined trigonometric expressions and deductive reasoning based on the principle of squaring of any real number.

Table 2: Statistical analysis for performance in trigonometry

\begin{tabular}{lllccccc}
\hline $\begin{array}{l}\text { Number } \\
\text { wrote }\end{array}$ & $\begin{array}{l}\text { Minimum } \\
\text { mark }\end{array}$ & $\begin{array}{l}\text { Lower } \\
\text { quartile }\end{array}$ & Median & $\begin{array}{c}\text { Upper } \\
\text { quartile }\end{array}$ & $\begin{array}{c}\text { Maximum } \\
\text { mark }\end{array}$ & $\begin{array}{c}\text { Mean } \\
\text { Standard } \\
\text { deviation }\end{array}$ \\
\hline 22 & 19 & 20 & 24.5 & 27.25 & 29 & 24.09 & 3.24 \\
\hline
\end{tabular}


Table 3: Statistical analysis for performance in calculus

\begin{tabular}{lllccccc}
\hline $\begin{array}{l}\text { Number } \\
\text { wrote }\end{array}$ & $\begin{array}{l}\text { Minimum } \\
\text { mark }\end{array}$ & $\begin{array}{l}\text { Lower } \\
\text { quartile }\end{array}$ & Median & $\begin{array}{c}\text { Upper } \\
\text { quartile }\end{array}$ & $\begin{array}{c}\text { Maximum } \\
\text { mark }\end{array}$ & $\begin{array}{c}\text { Mean } \\
\begin{array}{l}\text { Standard } \\
\text { deviation }\end{array}\end{array}$ \\
\hline 23 & 7 & 8 & 9 & 11 & 15 & 9.96 & 2.40
\end{tabular}

\section{Calculus}

The researchers present the tasks for calculus (see Box 4), followed by the statistical analysis (see Table 3 and Fig. 3) and discussion of data.

\section{Box 4: Calculus tasks}

1. For a function $y=f(x)$ explain what information the derivative $f^{1}(x)$ represents?

2. In the space provided use the rules for differentiation to find the derivative of the following each of the functions:

$2.1 \mathrm{y}=3 \chi^{2}-4$

$$
2.2 f(\chi)=\frac{\chi^{3}-2 \chi+1}{\chi}
$$$$
2.3 h(\chi)=x \stackrel{\chi}{(3 \chi}-4)
$$

3. Determine the equation of the tangent to the curve $g(x)=-3 \chi^{2}+2 \chi+1$ at the point where $\chi=0$

4. The sketch shows the graph of $\mathrm{y}=\mathrm{f}^{1}(\chi)$.

4.1 Determine the interval(s) over which function $\mathrm{f}$ is increasing.

4.2 Determine the value(s) of $\chi$ where the local maximum of $f$ occurs.

The following tasks (see Box 4) were answered well and contributed to the median of 9 out of a total of 15 (see Table 3): (a) differentiation techniques (number 2), (b) equation of the tangent (number 3). These tasks (numbers 2 and 3 in Box 4) were based on algorithmic procedures and relied on the application of rules. This implies that those teachers had a fairly good level of PCK encompassing algorithmic procedures. However, those teachers had an unsatisfactory level of PCK for the overall calculus tasks since $50 \%$ of those teachers achieved a score of $60 \%$ or below (see Table 3, median of 9). An examination of their written responses indicated that their overall unsatisfactory PCK was as a result of poor performance on tasks involving (a) definition of the derivative (number 1, Box 4), and (b) interpreting the graph of a derivative function (number 4, Box 4).

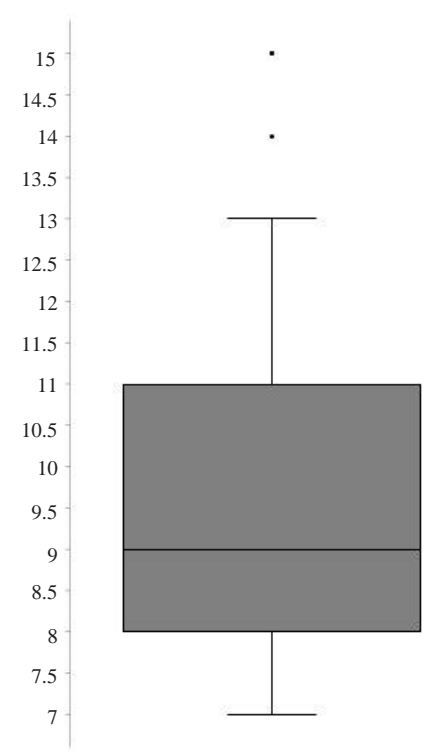

Fig. 3. Box and whisker illustrating performance in calculus

The researchers now investigate the spread of the marks as described by the box and whisker plot (see Fig. 4). The plot indicates that this data is more "skewed to the right". This simply means that the occurrence of higher marks is less than that of lower marks. In other words, their performance ranks relatively low on the calculus tasks. Each quartile marks $25 \%$ of the data, which implies that $50 \%$ of the teachers scored marks of 9 or less out of 15 and $25 \%$ of the teachers scored marks of 8 or less (see Table 3 , lower quartile of 8 ). The data contains some marks that are significantly higher than the rest and do not contribute toward the spread as they are deemed statistically higher than the norm (that is, outliers represented by the dots in Figure 3). Standard deviation refers to how much the data differs from the mean on average. Meaning most of the data is within the range [7.6, 12.4]. The general conclusion is that there was definitely room for improvement in the PCK of those teachers for calculus. 
With regard to the definition of the derivative, we found that most of those teachers had a problem defining this concept. This is significant because understanding what a derivative actually is goes a long way in terms of being able to work with it and interpret it. This implies that the PCK of the majority of those teachers lacked conceptual understanding of the derivative concept. The implication here is that teacher education should focus on the different interpretations of the derivative.

The consequence of poor conceptual understanding of the derivative contributed to those teachers' poor performance on tasks involving interpreting the graph of a derivative function (number 4, Box 4). Almost all of the teachers had the derivative with the properties of the original function $f$. This further confirms that the PCK of those teachers lacked conceptual understanding of the concept of the derivative. Of those who did understand what the graph was describing, most did not know how to go about using the graph of the derivative to make relevant conclusions about the properties of the original function. We illustrate an example of such a response in Figure 5. The student's responses (for 4.1 and 4.2) indicates that he/she prefers to work with the defining equation of the derivative function, $f^{1}(x)-x^{2}-4$, to make conclusions on the properties of the original function. This confirms, once again, those teachers reliance on algorithmic procedures which they seemed to be comfortable with. Note that it seems as though this teacher did not utilise the graph of the de-

4. The sketch shows the graph of $y=f^{1}(\chi)$.

4.1 Determine the interval(s) over which function $f$ is increasing

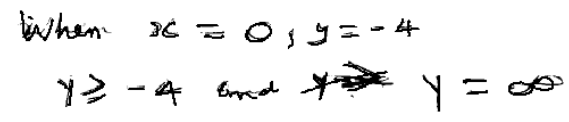

4.2 Determine the value(s) of $\chi$ where the local maximum of $f$ occurs.
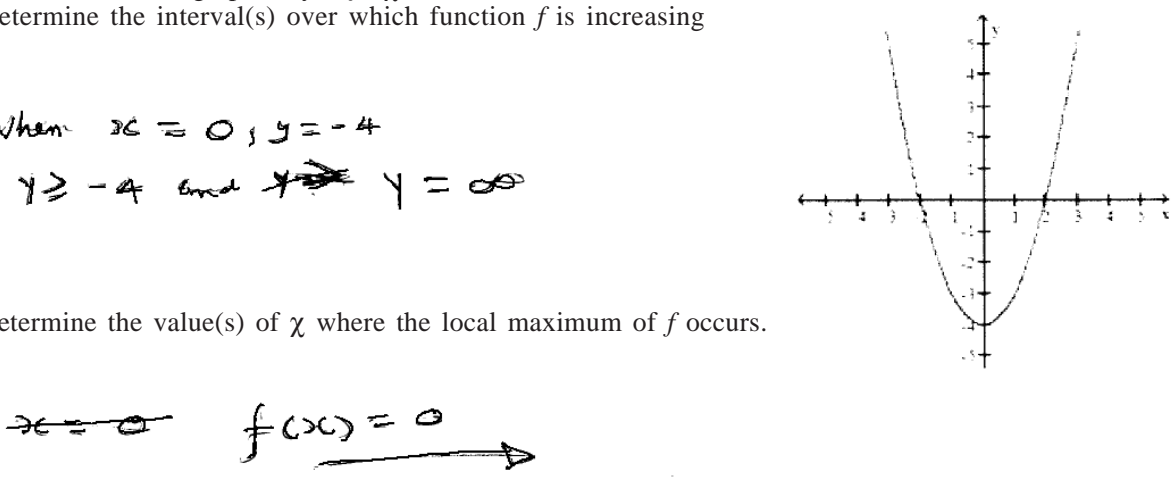

Fig. 4. An example of an inadequate response to interpreting the graph of a derivative function

4. The sketch shows the graph of $y=f^{2}(\chi)$.

4.1 Determine the interval(s) over which function $f$ is increasing

$$
\begin{aligned}
& f^{\prime}(x)=x^{2}-4 \\
& (-\infty ;-2) \text { and }(-\infty)
\end{aligned}
$$

4.2 Determine the value(s) of $\chi$ where the local maximum of $f$ occurs.

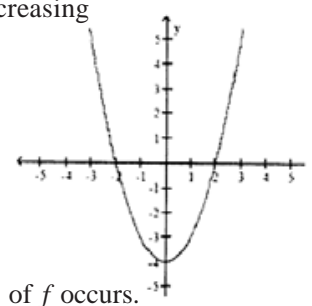

$$
\begin{gathered}
f^{\prime}(x)=x^{2}-4 \\
\text { For local max. } f^{\prime}(x)=0 \\
x^{2}-4=0 \\
(x-2)(x+2)=0 \\
x=2 \text { or }-2 \\
\therefore x=-2
\end{gathered}
$$

Fig. 5. An illustration of a teacher not knowing how to use the graph of a derivative function 
rivative to make the relevant conclusions about the original function. Further note that there is no verification by the teacher as to why yields the local maximum of .

\section{CONCLUSION}

The focused tasks in algebra, trigonometry and calculus were used as a basic support strategy to access the level of PCK of practising grade 12 mathematics teachers from underachieving schools. From the discussion of the data we were able to identify areas of strengths and weaknesses in the PCK of those teachers. Those strengths and weaknesses in PCK will be of benefit to mathematics teacher educators and practising teachers.

\section{RECOMMENDATIONS}

Although this case study was with a small group of practising teachers from underachieving schools, our feeling is that the findings apply to a wider context. Teacher educator courses should consider those weaknesses detected in the discussion of the data section of this paper. Emanating from that discussion the following aspects of PCK require attention: (a) solution of inequalities, (b) domain and range of functions, (c) correct use of mathematical notation, (d) principle of squaring of real numbers, (e) undefined trigonometric expressions, (f) deductive reasoning, (g) conceptual understanding of the derivative, and (h) interpretation of graphs of derivative functions to deduce the properties of the respective original function. The designed tasks could also serve as a catalyst for practising teachers to identify their areas of strengths and weaknesses with regard to their PCK. This assumes that practising teachers have the ability to reflect on their responses to such designed tasks and take corrective steps to improve the level of their PCK. It is crucial that practising teachers do not have the same misconceptions as pupils. The reason for that is a mathematics teachers' PCK should also include knowledge about what makes a particular topic easy or difficult for pupils to understand, the common misconceptions that pupils may have on a particular topic, and the strategies on how to deal with such issues.

\section{ACKNOWLEDGEMENTS}

This study was made possible by a grant received from ESKOM's Tertiary Education Support Programme (TESP) for the UKZN-ESKOM Mathematics Project. The researchers also thank Mr Moses Mogambery and Mr Dory Reddy for their assistance in conducting, organising and teaching the class, and marking of the tasks.

\section{REFERENCES}

Ball DL, Thames MH, Phelps G 2008. Content knowledge for teaching: What makes it special? Journal of Teacher Education, 59(5): 389-407.

Beswick K, Callingham R, Watson J 2012. The nature and development of middle school mathematics teachers' knowledge. Journal of Mathematics Teacher Education, 15: 131-157.

Brijlall D, Isaac V 2011. Links between content knowledge and practice in a mathematics teacher education course: A case study. South African Journal of Higher Education, 25(4): 680-699.

Cohen L, Manion L, Morrison K 2007. Research Methods in Education. $6^{\text {th }}$ Edition. London: Routledge.

Even R 1990. Subject matter knowledge for teaching and the case of functions. Educational Studies in Mathematics, 21(6): 521-544.

Henning E 2004. Finding Your Way in Qualitative Research. Pretoria: van Schaik.

Kilpatrick J, Swafford J, Findell B 2001. Adding It Up: Helping Children Learn Mathematics. Washington, D.C.: National Academy Press.

Kleickmann T, Richter D, Kunter M, Elsner J, Besser M, Krauss S, Baumert J 2013. Teachers' content knowledge and pedagogical content knowledge: The role of structural differences in teacher education. Journal of Teacher Education, 64(1): 90-106.

Long C 2003. Mathematics Knowledge For Teaching: How Do We Recognise This? Paper presented in Mathematical Knowledge for Teaching in University of Free State, Free State June 29 to July 3, 2009.

Maharaj A 2013. An Investigation into the Preparedness of Teachers to Teach Grade 12 Mathematics. Research Paper, Unpublished. Durban: University of KwaZulu-Natal. In review, Unpublished.

Maree K, Pieterson J 2007. Surveys and the use of questionnaires. In: K Maree (Ed.): First Steps in Research. Pretoria: van Shaik, pp. 145-153.

McNeill KL, Knight AM 2013. Teachers’ pedagogical content of scientific argumentation: The impact of professional development on K-12 teachers. Science Education, 97(6): 936-972.

Shulman L 1986. Those who understand: Knowledge growth in teaching. Educational Researcher, 15(2): 4-14.

Shulman L 1987. Knowledge and teaching: Foundation of the new reform. Harvard Educational Review, 57(1): 1-22.

Seidel RJ, Kett AL, Kett AL, Perencevich KC 2004. From Principles of Learning to Strategies for Instruction: Empirically Based Ingredients to Guide Instructional Development. New York: SpringerVerlag. 